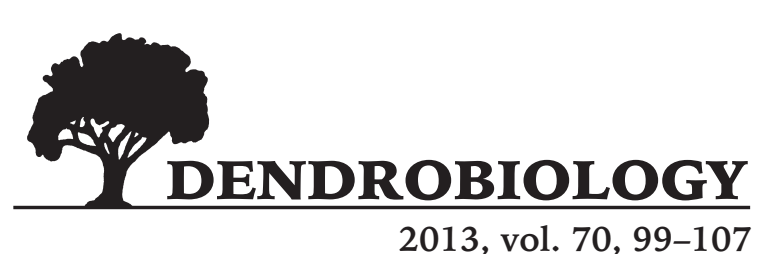

http://dx.doi.org/10.12657/denbio.070.011

\author{
Xiaoming Wang, Xiuhai Zhao*, Lushuang Gao
}

\title{
Climatic response of Betula ermanii along an altitudinal gradient in the northern slope of Changbai Mountain, China
}

Received: 06 January 2013; Accepted 25 April 2013

\begin{abstract}
The sensitivity of Betula ermanii tree-ring growth to climate variation over an altitudinal gradient was assessed. Betula ermanii forest grows in the northern slope of Changbai Mountain from approximately 1,700 $\mathrm{m}$ above sea level (a.s.l.), and forms the upper tree line at nearly 2,100 $\mathrm{m}$ a.s.l.. Six study sites were constructed along the altitudinal gradient (1,670 to 2,010 $\mathrm{m}$ a.s.l.) and ring-width chronologies of Betula ermanii were built. The mean tree-ring series intercorrelation (RBAR) increased with elevation. In principal component analysis, the first unrotated principle component explained $77.1 \%$ of the total variance, indicating the tree-ring growth of Beutla ermanii over the altitudinal gradient was governed by regional climate. Correlation function analysis revealed that the radial growth of Betula ermanii was significantly similar in response to climatic conditions. Overall, the low temperatures during previous June, July and during the dormant period (previous October to current May) and the high temperatures during current June, July and August would benefit the radial growth of Betula ermanii. Abundant precipitation during growing season (previous June, July, September and current August), previous November and current May, would also facilitate the tree-ring growth. The reason for this uniform growth behavior in Betula ermanii remained unclear. Betula ermanii in Changbai Mountain formed relatively pure stands with an open canopy, which might be partly contributing to the common growth response to climatic signals along the altitudinal gradient, but further work was required for testing this assumption.
\end{abstract}

Additional key words: temperature, precipitation, dendroclimatology, tree line, tree ring

Addresses: X.M. Wang, X.H. Zhao*, L.S. Gao, Key Laboratory for Silviculture and Conservation of Ministry of Education, Beijing Forestry University, Beijing 100083, P. R. China, e-mail: bfuz@163.com; wxming35@gmail.com

*corresponding author

\section{Introduction}

Mountainous ecosystems, with abundance of woody species distributing across wide altitudinal ranges, are considered to be sensitive to climatic changes. Using dendrochronological technologies, plenty of studies have been conducted in subalpine to alpine area to explore the growth response to climate conditions. But most of them were carried out in sites under extremely high environmental stress, such as the altitudinal tree-lines, with the objective of looking for trees whose growth were maximumly limited by climate (Fritts 1976). As a matter of fact, this operation could probably lead to a biased conclusion if we want to understand the growth-climate relationship on the local landscape, population or ecosystem scale .Because the growth response of climate-stressed trees under their distribution margin cannot repre- 
sent the growth response of the whole landscape population (Wilmking et al. 2004). It has been proved by increasing studies that the climate/tree growth relationships are not consistent along altitudinal gradient (Fritts et al. 1965, Fritts 1976, Kienast et al. 1987, Zhang and Hebda 2004, Wang et al. 2005, Yu et al. 2007, Peng et al. 2008, Carrer et al. 2010). Typically, radial growth at low-elevations was more related to precipitation-relevant variables, and changes into temperature-related variables at high-elevations (Zhang and Hebda 2004, Wang et al. 2005, Yu et al. 2007, Carrer et al. 2010). However, some studies on conifer trees found uniform growth responses to climate along the altitudinal gradient in central Asian and in southeastern Tibetan Plateau (Liu et al. 2006, Esper et al. 2007, Liang et al. 2010). Consequently, researches should be efficiently organized along subalpine to alpine ecological gradients to get more clues about the altitude-related climate signals in tree growth.

Betula ermanii, a deciduous broad-leaved tree species, is widely distributed in Changbai Mountain, Northeast China and is maintaining an important role in local ecosystem. Above subalpine coniferous forest, it forms open woodlands of more than $300 \mathrm{~m}$ in vertical width, and invades to the uppermost limit of tree growth at nearly $2,100 \mathrm{~m}$ a.s.l., providing ideal places and materials for the dendroclimatical study (Wu et al. 2009). Unfortunately, such studies on $B$. ermanii are in a shortage, and most of which were developed at upper tree-lines (Takahashi et al. 2005; Yu et al. 2005; Yu et al. 2007), which could not give a thorough interpreting of the dendroclimatical features of Betula ermanii. With the objective to explore the climatic factors affecting variation in tree-ring growth and to identify whether these factors differ with altitude, we performed a dendroclimatic analysis on Betula ermanii in the northern slope of Changbai Mountain $\left(41^{\circ} 31^{\prime}-42^{\circ} 28^{\prime} \mathrm{N}, 127^{\circ} 9^{\prime}-128^{\circ} 55^{\prime} \mathrm{E}\right)$.

\section{Methods}

Changbai Mountain, as one of the most complete natural ecosystems in China, is featured by a typical temperate mixed forest ecosystem. The climate of the Changbai Mountain is characterized by a cold and long winter period and a short and rainy summer period. The annual mean temperature ranges from -8.6 to $-5.2^{\circ} \mathrm{C}$. The highest and the lowest temperature occurred in July and in January, respectively. Annual precipitation is from 700 to $1,500 \mathrm{~mm}$ (Fig. 1). The frost-free period ranges from 65-70 days.

Six forest sites along an altitude gradient (1,670-2,010 $\mathrm{m}$ a.s.1.), on the northern slope of Changbai Mountain, were selected for this study (Table 1). These sites were vertically throughout the local Betula ermanii population and encompassed its upper and lower distribution limits (namely tree-lines). The sites representing lower and upper tree-line were

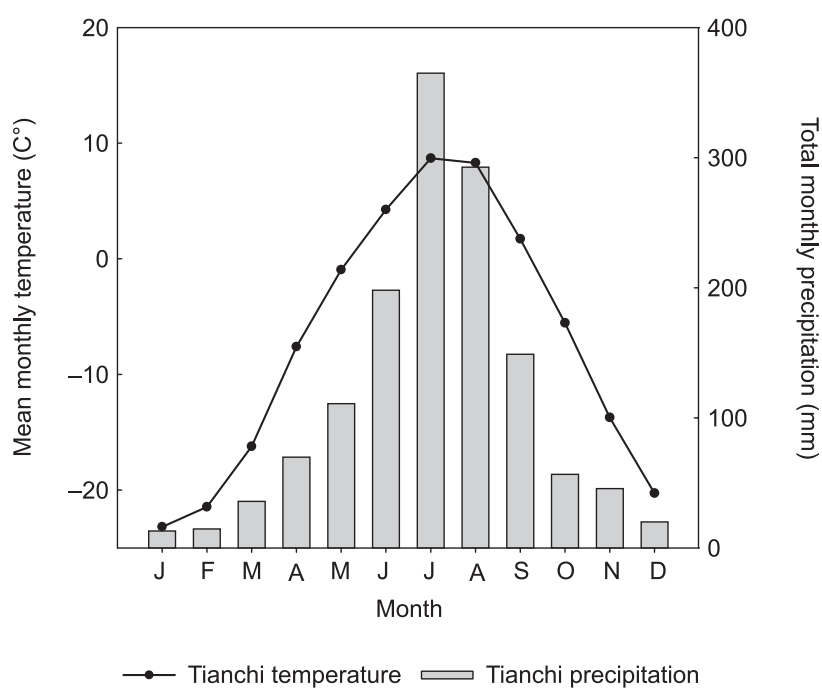

Fig. 1. Monthly total precipitation and mean monthly temperature at Tianchi Meteorological station in Changbai Mountain, averaged from 1959 to 2009

Table 1. Summary statistics for the six Betula ermanii (Be) residual chronologies

\begin{tabular}{lcccccc}
\hline \multicolumn{1}{c}{ Site code } & Be1670 & Be1740 & Be1830 & Be1890 & Be1950 & Be2010 \\
\hline Altitude (m a.s.l.) & 1670 & 1740 & 1830 & 1890 & 1950 & 2010 \\
Number of cores/trees & $33 / 22$ & $25 / 16$ & $25 / 16$ & $40 / 21$ & $29 / 16$ & $31 / 18$ \\
Chronology length & AD1874-2010 & AD1782-2010 & AD1809-2010 & AD1787-2009 & AD1804-2010 & AD1840-2008 \\
Mean ring width (mm) & 1.063 & 0.543 & 0.743 & 0.709 & 0.556 & 0.550 \\
Mean sensitivity (MS) & 0.2961 & 0.3326 & 0.2758 & 0.3419 & 0.342 & 0.2996 \\
$\begin{array}{l}\text { Express population signal (EPS) } \\
\text { Mean correlations between trees }\end{array}$ & 0.95 & 0.942 & 0.945 & 0.968 & 0.969 & 0.952 \\
(RBAR) & 0.366 & 0.416 & 0.407 & 0.432 & 0.516 & 0.511 \\
$\begin{array}{l}\text { First year SSS }>0.85 \\
\text { (min Num. of samples) }\end{array}$ & $1911(9)$ & $1817(8)$ & $1857(8)$ & $1826(8)$ & $1841(6)$ & $1867(6)$ \\
Gini coefficient & 0.505 & 0.510 & 0.508 & 0.510 & 0.509 & 0.507 \\
\hline
\end{tabular}


on the elevation of 1,670 and 2,010 $\mathrm{m}$ a.s.1., respectively. And the other four sites lined up between them were considered to represent the main dominant zone of Betula ermanii. At each site, 20-25 adult trees were chosen for our analysis and two cores were extracted at breast height (about $1.3 \mathrm{~m}$ from ground level) from each tree using an increment borer.

In the laboratory, all cores were mounted and polished, then the tree-ring widths were measured under a precision of $0.001 \mathrm{~mm}$. The measured tree-ring series were quality-checked and cross-dated by the COFECHA software (Holmes 1983). The cores of poor quality (e.g., fragmented, rotted) were excluded from the further analysis. The program ARSTAN (Cook 1985) was used to get ring-width chronology of Betula ermanii for each site. In order to eliminate or minimize the long-term and low-frequency variation caused by tree age, disturbance and competition between neighboring trees, etc., each of the raw series was individually detrended by a 40-year cubic smoothing spline and the degree of smoothing was fixed at $50 \%$ frequency response. Then by calculating a biweight robust mean for each site to further remove the random signals related to local disturbances (Cook and Kairiukstis 1990), residual chronologies were developed to maximize the climatic signal. Figure 2 represents the tree-ring width residual chronologies from six altitudinal sites respectively.

Several statistics were calculated for each of the six residual chronologies. The mean sensitivity (MS) is

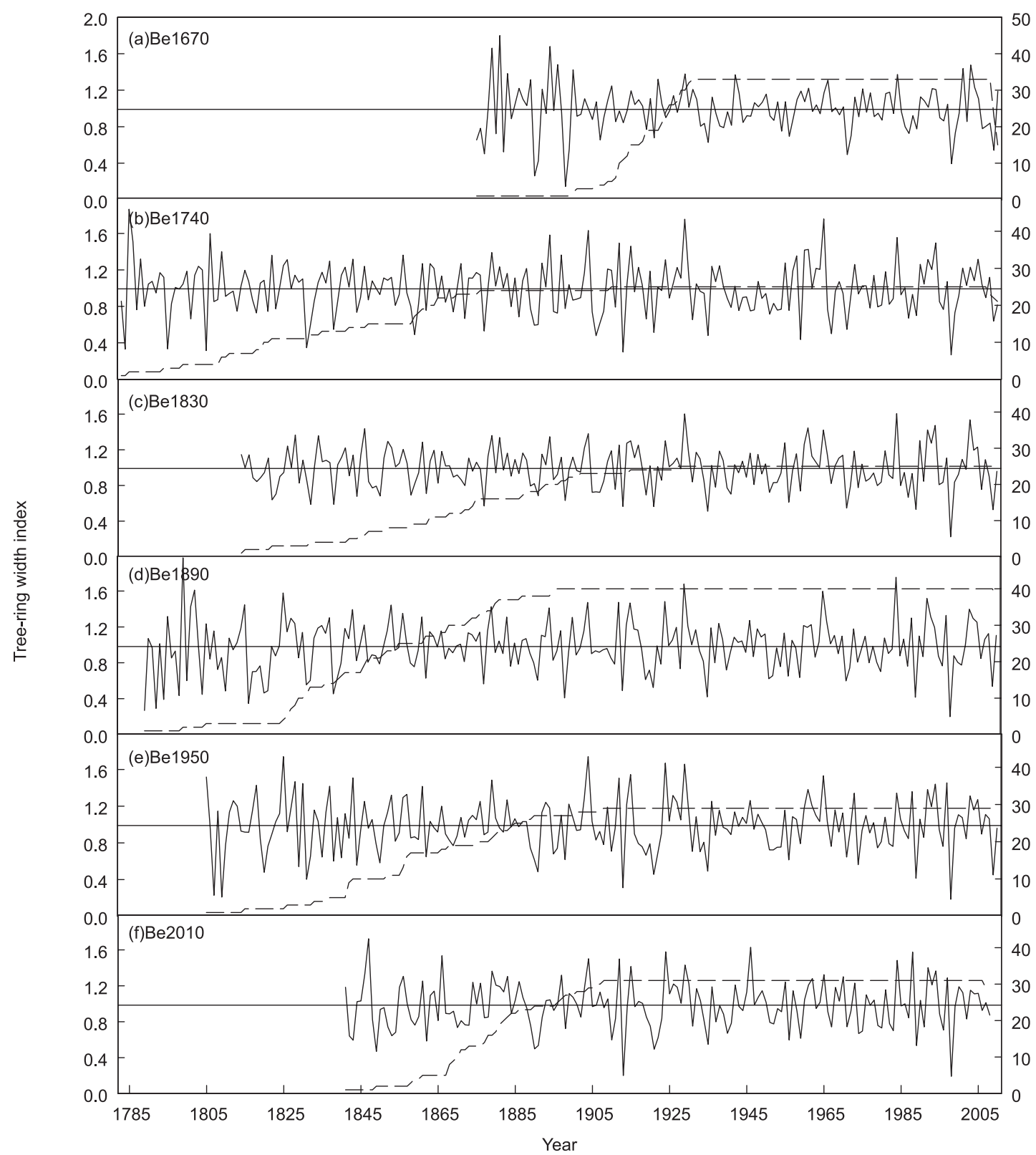

Fig. 2. Tree-ring width residual chronologies of Betula ermanii with sample depth (number of cores), ordered according to the site altitude. Solid lines represented the tree-ring width indices, the dotted line represented the sample depth. (a) Be 1670, (b) Be 1740, (c) Be 1830, (d) Be 1890, (e) Be 1950, (f) Be 2010 
an evaluation of year-to-year variability in tree-ring width (Fritts 1976), and according to Ferguson's classification, a mean sensitivity greater than 0.3 is considered to be high (Savva et al. 2006). The mean series intercorrelation (RBAR) and the Expressed Population Signal (EPS) are used to measure the reliability of each residual chronology (Cook and Kairiukstis 1990). RBAR is the mean correlation coefficient among tree-ring series. EPS measures to what extent the finite-sample chronology could be representative of the theoretical population chronology based on an infinite number of trees (Wigley et al. 1984). A chronology with an EPS $>0.85$ is often considered to be reliable (Cook and Kairiukstis 1990). To assess the adequacy of replication in the early years of the six chronologies, we cited the index of Subsample Signal Strength (SSS) (Wigley et al. 1984). We limited our analysis to the period with SSS $>0.85$ (Wigley et al. 1984). Besides, the Gini coefficient of each chronology was calculated by using the gini.coef function in the dplR package (Bunn et al. 2012). Different from the index of mean sensitivity, which refers only to adjacent rings, the Gini coefficient quantitatively describes all-lag sensitivity of the tree-ring series (Biondi and Qeadan 2008).

The closest meterorological station to our study sites is Tianchi $\left(42^{\circ} 01^{\prime} \mathrm{N}, 128^{\circ} 05^{\prime} \mathrm{E}, 2623 \mathrm{~m}\right.$ a.s.1.), but the climate records cover a relatively short period (1959-2009). So the climate data generated from the CRUts2.1 (Mitchell and Jones 2005) were used. It was a gridded dataset based on instrumental data from hundreds of precipitation and temperature stations throughout the Alps and Apennines, which were subjected to homogeneity tests and relative adjustments, and finally gridded on a $0.5 * 0.5$ degree network (Carrer et al. 2010). Monthly total precipitation and mean air temperature were available for the period of 1902-2002 from the closest grid point $\left(42^{\circ} 25^{\prime} \mathrm{N}, 128^{\circ} 25^{\prime} \mathrm{E}\right)$ to our sites. The climate data were highly correlated with the locally observed data at Tianchi (for temperature: $r=0.920, n=528$ months, $P<0.001$ and for precipitation: $r=0.763$, $\mathrm{n}=528$ months, $P<0.001)$.

A principal component analysis (PCA), based on the correlation matrix of the six residual chronologies, was used to explore common causes of variability in annual radial growth. The analysis period was from 1911 to 2002, when all chronologies had an SSS $>0.85$. Only the components that explained $\geq 5 \%$ of the variation in the original variables were retained, a criterion previously used in similar dendrochronological studies (Peterson and Peterson 2001). Using this criterion, only the first three principal components were retained; these axes were then rotated orthogonally using the varimax criterion, which refines the PC axes and enables a better spatial interpretation of the loadings (Richman 1986).
To examine the climate/tree-ring growth relationships, standard Correlation Function (CF) analysis was performed between monthly climate variables and tree-ring indices. This analysis was achieved via the software program DENDROCLIM2002 (Biondi and Waikul 2004). The bootstrap method (Efron and Tibshirani 1986, Guiot 1991), with 1,000 iterations, was used for significance testing, and all statistical procedures were evaluated at $P<0.05$ level of significance. A 16-month window of climate variables was selected, spanning from June of the previous year to September of the current growing season.

\section{Results}

Summary statistics of the six residual chronologies were listed in Table 1. The mean length of series ranged from 94 to 175 years. The mean ring width decreased from 1.063 to $0.543 \mathrm{~mm}$ with ascending elevations, although this decreasing trend was not significant $(P>0.05)$ (Fig. 3). All chronologies had a relatively high value of mean sensitivity, ranging from 0.28 to 0.34 , and mean sensitivity was not significantly correlated with elevation $(P>0.05)$ (Fig. 3). The mean correlation between trees ranged from 0.366 to 0.516 , and significantly positively correlated with elevation $(P<0.05)$ (Fig. 3$)$. The expressed population signal was equal to or above 0.95 for all chronologies, indicating a reliable estimation of the population size for all chronologies. Partial correlation analysis indicated that tree age appeared not to affect the relationships between these four statistics and elevation. The Gini coefficient was highly consistent among all chronologies, which was about 0.51 , indicating the diversity in tree-ring series had little difference among sites. The six residual chronologies were truncated at the first year with subsample strength (SSS) $>0.85$.

A PCA performed on the six residual chronologies revealed that the year-to-year variability in tree-ring series could be summarized into three representative principal components (PCs) (Fig. 4). The first three unrotated PCs explained 77.102, 10.086, and 6.578\% of the total variance respectively. Cumulatively they explained $93.764 \%$ of total variance. After rotation, the first three varimax loadings explained 43.240, 28.174 , and $22.351 \%$ of the variance respectively.

The radial growth/climate relationships were calculated over the SSS $>0.85$ period (1911-2002) and showed in Fig. 5. A strong summer (current June, July and August) temperature signal was explored across these chronologies. June mean temperature showed a positive impact on all six chronologies. July and $\mathrm{Au}-$ gust mean temperatures were positively correlated with five and two chronologies, respectively. Negative influence of the mean temperature in the early growing season of the previous year (previous June and 

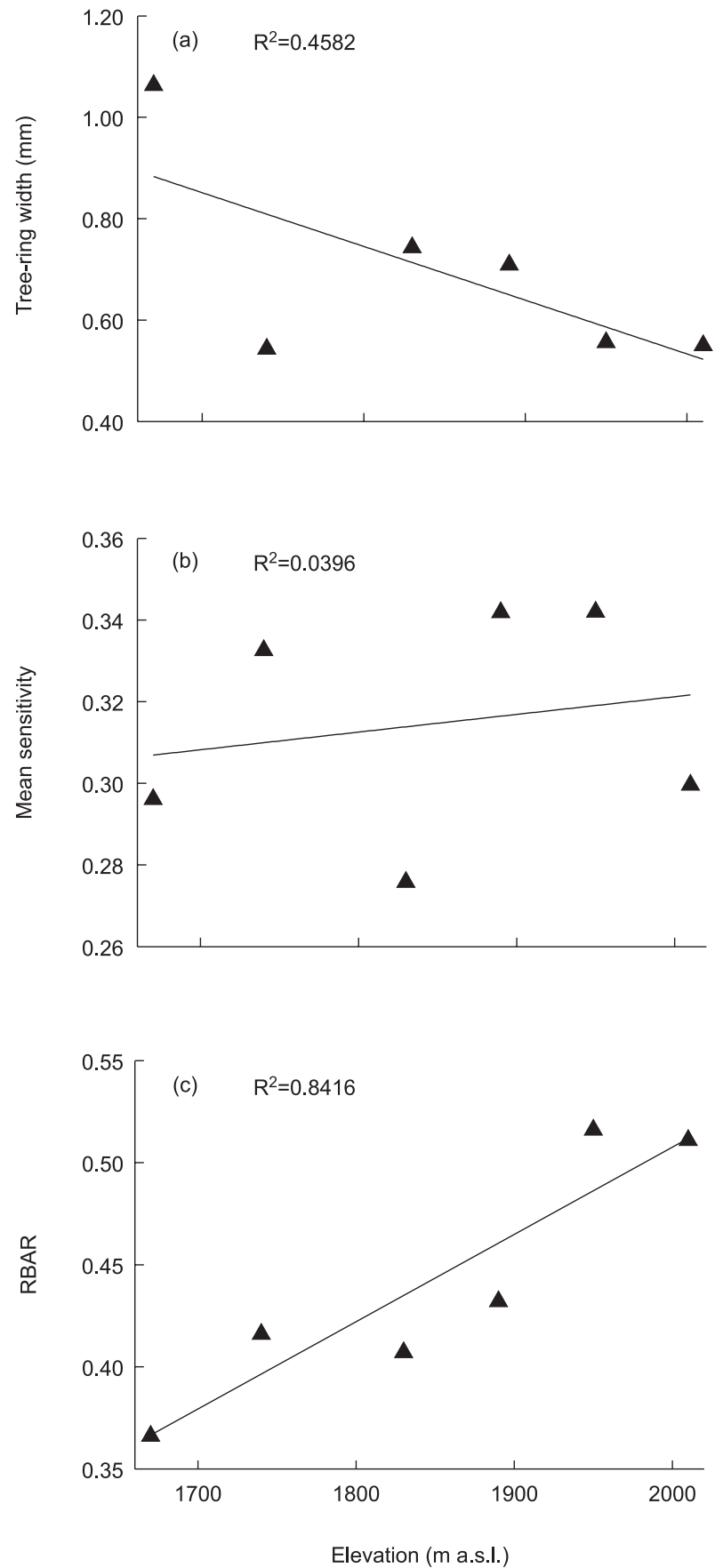

Fig. 3. Variation in mean ring width (a), mean sensitivity (b) and mean correlation between tree-ring series (RBAR) (c) along altitudinal gradients

July) was revealed in four of the six sites. Besides, chronologies of the sites on 1,740, 1,950 and 2,010 m a.s.l. were positively correlated with previous September mean temperature, which was of the end of the growing season. High temperatures during non-growth season (from previous October to current May) limited growth.

In general, the radial growth of Betula ermanii across the altitudinal gradient was positively correlated with precipitations in previous June, July, September and November and in current May and Au-

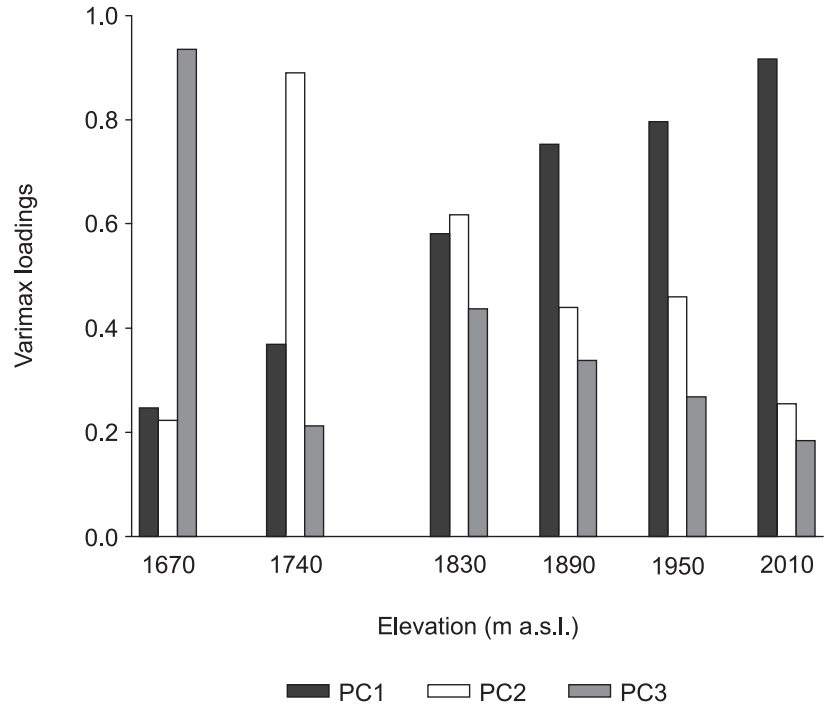

Fig. 4. Varimax loadings for the first three principal components from the six Betula ermanii chronologies

gust. Whereas high precipitation in current June limited the tree-ring growth on 2,010 $\mathrm{m}$ a.s.l.

\section{Discussion and conclusions}

Our study found a deceasing trend in mean ring width values with increasing elevation, which was frequently observed along altitudinal gradients (Splechtna et al. 2000; Gou et al. 2005; Wang et al. 2005; Di Filippo et al. 2007; Liang et al. 2010). Mainly because that at high elevations, the tree-ring formation was limited by many factors, such as the low temperature, strong wind exposure, shallow soil with low nutrient availability, and shortened growing season (Di Filippo et al. 2007; Liang et al. 2010).The relationship between RBAR and elevation also suggested that environmental conditions at higher elevation sites were more stressful for Betula ermanii growth.

Despite differences in dendrochronological statistics among the chronologies, a high degree of coherence in tree-ring growth was shown across the altitudinal gradient (Fig. 2). The measurement of Gini coefficient indicated the all-lag sensitivity of each chronology to environmental changes might be equal, which was independent of altitude. In PCA, the total variance explained by the first unrotated component was high $(77.1 \%)$, compared with some other studies along altitudinal gradients (Mäkinen et al. 2002; Di Filippo et al. 2007; Leal et al. 2007). It was most likely to reflect that the regional climate variation, independent of stand elevation, was responsible for such a similar spatial response. Correlation function analysis confirmed that differences in site altitude did not appear to modulate the strength of the growth response of Betula ermanii to climate. The common growth-climate relationships throughout the altitudinal gradient were characterized by the 


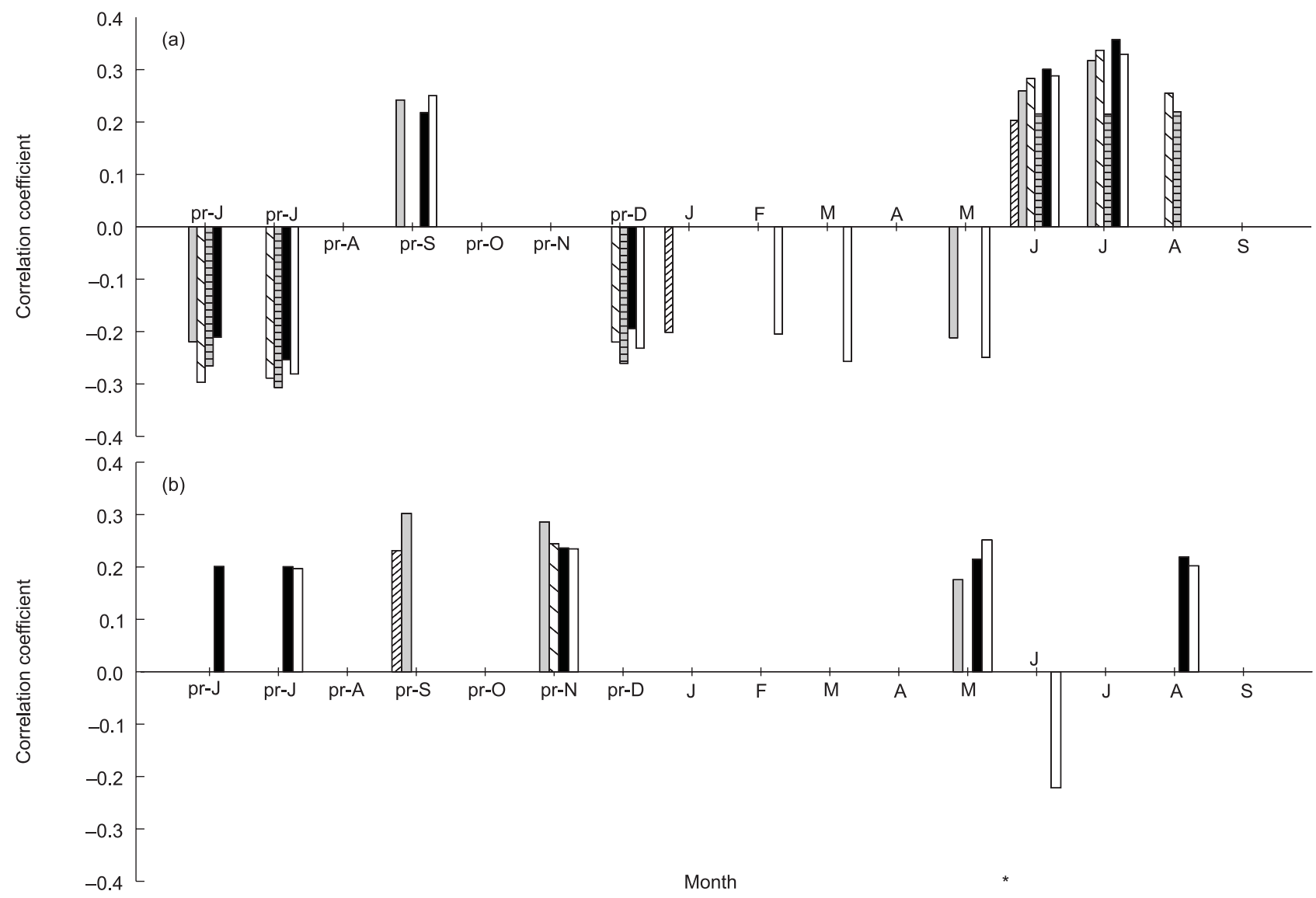

एבIIIA Be1670 $\square$ Be1740 $\backslash \backslash$ Be1830 $\rightleftharpoons$ Be1890 Be1950 $\square$ Be2010

Fig. 5. Correlation function results. Coefficients were computed over the period of 1911-2002 between the six residual chronologies and (a) the monthly mean temperature variables (b) the monthly precipitation variables. Only statistically significant correlation coefficient values were showed $(P<0.05)$. ( $\mathrm{pr}$ stands for previous year climate variables)

negative growth response to high temperature during previous growing season and dormant season, positive growth response to temperature during current growing season, and positive growth response to high amount of precipitation.

The tree-ring growth of Betula ermanii positively correlated with current summer (June to August) temperature. Many researchers also found that high summer temperature was favored by tree growth at high altitudes and high latitudes (Gostev et al. 1996; Barber et al. 2004; Chen et al. 2011). Photosynthetic rates of plants are generally temperature dependent, high temperatures during the growing season will enhance photosynthetic production for alpine and subalpine plants (DeLucia and Smith 1987). And cambial activity (cell division) is generally slow under cold conditions (Takahashi et al. 2011).

Temperatures of previous December and current May were negatively correlated with radial increment of Betula ermanii. General explanations existed in: 1) high temperatures in late winter and early spring would increase respiration and evapotranspiration sometimes, when the carbohydrate-losses in tree body cannot be replaced by photosynthesis and water uptake (Mäkinen et al. 2002), and 2) warm spring temperatures could promote photosynthesis and respiration while roots are still too cool to be efficient in water uptake, inducing stress dehydration and loss of carbon reserves (Carrer et al. 1998). Negative effects of warmer temperatures in dormant season in high-altitude environments have also been reported by other authors (Carrer et al. 1998; Mäkinen et al. 2002; Savva et al. 2006; Oberhuber et al. 2008).

Some researchers have pointed out that tree-ring growth was affected not only by the climatic conditions of the current year but also by those of the previous year (Rolland 1993; Savva et al. 2006; Chen et al. 2011). This view was confirmed in our study, as radial growth of Betula ermanii was closely related with climate of previous growing season. Statistical relationships pointed to a negative effect of previous June and July mean temperature. However the underlying reason was unclear. A negative relationship between beech species growth and previous summer temperature has also been reported without providing an explanation (Cullen et al. 2001; Di Filippo et al. 2007). 
Generally positive correlations were found between tree growth and precipitation during growing season (previous June, July, September and current August). Mainly because high level of precipitation during summer would release the drought stress caused by high temperature (Takahashi et al. 2003). Previous November and current May precipitation both had positive influences. Precipitation during previous November and current May took the form of snow, and we considered that the positive growth response to a large amount of snow might be due to the insulating effect of snow cover in preventing low soil temperatures, rather than in increasing water availability, which is rarely a limiting factor during winter (Carrer et al. 1998). Warmer soil condition might be conducive to the survival of winter bud and would lead to a longer period of root inactivity to further protect the root system from damage caused by severe coldness (Yu et al. 2007). Some studies reported that winter precipitation positively affected radial growth of $P$. jezoensis and Betula species (Takahashi et al. 2003, Yu et al. 2005, Cedro 2007). Oberhuber et al. (2008) also considered that low winter precipitation could be a trigger for radial growth depression. At the site of 2,010 m a.s.l., the tree-ring widths of Betula ermanii had a negative correlation with June precipitation. Coincidentally, this negative correlation to current summer precipitation was also found in some regions (Mäkinen et al. 2000, Miina 2000, Mäkinen et al. 2003, Koprowski and Zielski 2006). However, there was no significant partial correlation between June precipitation and tree growth when June temperature was controlled $(-0.107, P=0.313)$.

It has been reported by many studies that the radial growth/climate relationship was clearly altitudinal-related (Mäkinen et al. 2002; Linderholm et al. 2003; Tardif et al. 2003; Liu et al. 2006). While in our study, difference in site altitude did not appear to modulate the strength of the growth response of Betula ermanii to climate. Similar conclusions have been drawn by some researches. Esper et al. (2007) examined ring-width chronologies of juniper trees in lower ( $\sim 2,860 \mathrm{~m}$ a.s.l.) and higher $(\sim 3,440 \mathrm{~m}$ a.s.l.) elevation environments in western central Asia and found a uniform growth between them, which might be forced by solar radiation variations controlled via cloud cover changes. Liu et al. (2006) reported a significant similarity in climate-growth relationships of Sabina przewalskii Kom. at its upper $(4,140 \mathrm{~m}$ a.s.l.) and lower $(3,858 \mathrm{~m}$ a.s.l.) tree lines in northeastern Qinghai-Tibetan Plateau. Liang et al. (2010) found common climatic signals in a network of Smith fir chronologies from sites ranging from 3,550 to 4,390 $\mathrm{m}$ a.s.l. Currently, there seems no solid explanation for this phenomenon of capturing common environmental signals in tree growth along elevational gradients. In Changbai Mountain, Betula ermanii formed open woodlands of more than $300 \mathrm{~m}$ along the altitude. A study by Yu et al. (2005) showed that on the elevation of 1,950 $\mathrm{m}$ a.s.l., the forest consist of $95 \%$ Betula ermanii trees. The relatively pure stands coupled with an open canopy (about $40 \%$ canopy cover) may indicate the competition, both intra- and inter-species, for resources availability (e.g., sunlight, water, nutrient) is reduced. It has been suggested that competition may modulate the effect of climate conditions (e.g., drought) on the tree growth, although it is far too early to draw a general conclusion on how competition works (Martin-Benito and Cherubini 2008). According to Olivar et al. (2012), suppressed trees received lower solar radiation and higher wind protection by the influence of neighbouring crowns reducing transpiration rates, therefore, climatic sensitivity might be reduced. From this respect, the common growth response to climate in our case may be partly explained by the less competitive stress. However, more investigations would be required to test this assumption.

In conclusion, the results of this study showed that the radial growth of Betula ermanii was benefited from low temperature during previous June, July, December and current May, and from high temperature during current June to August. Precipitation was also a limiting factor for Betula ermanii growth over the elevational gradient, as high level of precipitation during previous and current growing season (previous June, July, September and current August), as well as during previous November and current May was favored. Such macroclimate-driven tree growth response to climate would facilitate future studies on reconstruction of quantified climate variability in Changbai Mountain. We are aware that the present study may not provide a solid answer to the issue of growth similarity along altitudinal gradient, and more investigations will greatly improve our knowledge of growth response to environmental changes.

\section{Acknowledgments}

The authors thank the Special Research Program for Forestry Welfare of China (Grant No. 200904022; 201004002) and the 12th five-year National Science and Technology plan of China (Grant No. 2012BAC01B03) for support.

\section{References}

Barber V.A., Juday G.P., Finney B.P., Wilmking M. 2004. Reconstruction of summer temperatures in interior Alaska from tree-ring proxies: evidence for changing synoptic climate regimes. Climatic Change 63: 91-120.

Biondi F., Qeadan F. 2008. Inequality in paleorecords. Ecology 89: 1056-1067. 
Biondi F., Waikul K. 2004. DENDROCLIM2002: A $\mathrm{C}++$ program for statistical calibration of climate signals in tree-ring chronologies. Computers \& Geosciences 30: 303-311.

Bunn A.G., Korpela M., Biondi F., Campelo F., Merian, P., Qeadan, F., Zang, C. 2012. dplR: Dendrochronology Program Library in $\mathrm{R}$, in: $\mathrm{R}$ package version 1.5.4, available at: http://CRAN.R-project.org/package $=$ dplR (last access: 3 April 2013).

Carrer M., Nola P., Motta R., Urbinati C. 2010. Contrasting tree-ring growth to climate responses of Abies alba toward the southern limit of its distribution area. Oikos 119: 1515-1525.

Carrer M., Anfodillo T., Urbinati C., Carraro V. 1998. High-altitude forest sensitivity to global warming: results from long-term and short-term analyses in the eastern italian alps. In: The Impacts of Climate Variability on Forests. Beniston M., Innes J. (Eds.). Springer Berlin, Heidelberg, pp. $171-189$.

Cedro A. 2007. Tree-ring chronologies of downy oak (Quercus pubescens), pedunculate oak (Q. robur) and sessile oak (Q. petraea) in the Bielinek Nature Reserve: Comparison of the climatic determinants of tree-ring width. Geochronometra 26: 39-45.

Chen L., Wu S., Pan T. 2011. Variability of climate-growth relationships along an elevation gradient in the Changbai Mountain, northeastern China. Trees 25: 1133-1139.

Cook E.R. 1985. A Time Series Analysis Approach to Tree Ring Standardization. Doctoral Dissertation. University of Arizona, Tucson.

Cook E.R., Kairiukstis L.A. 1990. Methods of dendrochronology:applications in the environmental sciences. Kluwer, Dordrecht, pp. 137-148.

Cullen L.E., Palmer J.G., Duncan R.P., Stewart G.H. 2001. Climate change and tree-ring relationships of Nothofagus menziesii tree-line forests. Canadian Journal of Forest Research 31: 1981-1991.

DeLucia E.H., Smith W.K. 1987. Air and soil temperature limitations on photosynthesis in Engelmann spruce during summer. Canadian Journal of Forest Research 17: 527-533.

Di Filippo A., Biondi F., Čufar K., De Luis M., Grabner M., Maugeri M., Presutti Saba E., Schirone B., Piovesan G. 2007. Bioclimatology of beech (Fagus sylvatica L.) in the Eastern Alps: spatial and altitudinal climatic signals identified through a tree-ring network. Journal of Biogeography 34: 1873-1892.

Efron B., Tibshirani R. 1986. Bootstrap methods for standard errors, confidence intervals, and other measures of statistical accuracy. Statistical Science 1: 54-57.
Esper J., Frank D., Wilson R., Büntgen U., Treydte K. 2007. Uniform growth trends among central Asian low- and high-elevation juniper tree sites. Trees - Structure and Function 21: 141-150.

Fritts H.C., Smith D.G., Cardis J.W., Budelsky C.A. 1965. Tree-ring characteristics along a vegetation gradient in northern Arizona. Ecology 46: 394-401.

Fritts H.C. 1976. Tree rings and climate. Academic Press, New York.

Gostev M., Wiles G., D’arrigo R., Jacoby G., Khomentovsky P. 1996. Early summer temperatures since 1670 A.D. for Central Kamchatka reconstructed based on a Siberian larch tree-ring width chronology. Canadian Journal of Forest Research 26: 2048-2052.

Gou X., Chen F., Yang M., Li J., Peng J., Jin L. 2005. Climatic response of thick leaf spruce (Picea crassifolia) tree-ring width at different elevations over Qilian Mountains, northwestern China. Journal of Arid Environments 61: 513-524.

Guiot J. 1991. The bootstrapped response function. Tree-Ring Bulletin 51: 39-41.

Holmes R.L. 1983. Computer-assisted quality control in Tree-Ring dating and measurement. Tree-Ring Bulletin 43: 69-78.

Kienast F., Schweingruber F.H., Bräker O.U., Schär E. 1987. Tree-ring studies on conifers along gradients and the potential of single-year analyses. Canadian Journal of Forest Research 17: 683-696.

Koprowski M., Zielski A. 2006. Dendrochronology of Norway spruce (Picea abies (L.) Karst.) from two range centres in lowland Poland. Trees - Structure and Function 20: 383-390.

Leal S., Melvin T.M., Grabner M., Wimmer R., Briffa K.R. 2007. Tree-ring growth variability in the Austrian Alps: the influence of site, altitude, tree species and climate. Boreas 36: 426-440.

Liang E., Wang Y., Xu Y., Liu B., Shao X. 2010. Growth variation in Abies georgei var. smithii along altitudinal gradients in the Sygera Mountains, southeastern Tibetan Plateau. Trees 24: 363-373.

Linderholm H.W., Solberg B., Lindholm M. 2003. Tree-ring records from central Fennoscandia: the relationship between tree growth and climate along a west-east transect. The Holocene 13: 887-895.

Liu L.-S., Shao X.-M., Liang E.-Y. 2006. Climate signals from tree ring chronologies of the upper and lower treelines in the Dulan region of the Northeastern Qinghai-Tibetan Plateau. Journal of Integrative Plant Biology 48: 278-285.

Martin-Benito D., Cherubini P., Delrio M., Canellas I. 2008. Growth response to climate and drought in Pinus nigra Arn. trees of different crown classes. Trees 22: 363-373. 
Mäkinen H., Nöjd P., Mielikäinen K. 2000. Climatic signal in annual growth variation of Norway spruce (Picea abies) along a transect from central Finland to the Arctic timberline. Canadian Journal of Forest Research 30: 769-777.

Mäkinen H., Nöjd P., Kahle H.-P., Neumann U., Tveite B., Mielikäinen K., Röhle H., Spiecker H. 2002. Radial growth variation of Norway spruce (Picea abies (L.) Karst.) across latitudinal and altitudinal gradients in central and northern Europe. Forest Ecology and Management 171: 243-259.

Mäkinen H., Nöjd P., Kahle H.-P., Neumann U., Tveite B., Mielikäinen K., Röhle H., Spiecker H. 2003. Large-scale climatic variability and radial increment variation of Picea abies (L.) Karst. in central and northern Europe. Trees - Structure and Function 17: 173-184.

Miina J. 2000. Dependence of tree-ring, earlywood and latewood indices of Scots pine and Norway spruce on climatic factors in eastern Finland. Ecological Modelling 132: 259-273.

Mitchell T., Jones P. 2005. An improved method of constructing a database of monthly climate observations and associated high-resolution grids. International Journal of Climatology. 25: 693-712.

Oberhuber W., Kofler W., Pfeifer K., Seeber A., Gruber A., Wieser G. 2008. Long-term changes in tree-ring-climate relationships at Mt. Patscherkofel (Tyrol, Austria) since the mid-1980s. Trees - Structure and Function 22: 31-40.

Olivar J., Boginoc S., Spieckerb H., Bravoa F. 2012. Climate impact on growth dynamic and intra-annual density fluctuations in Aleppo pine (Pinus halepensis) trees of different crown classes. Dendrochronologia 30: 35-47.

Peng J., Gou X., Chen F., Li J., Liu P., Zhang Y. 2008. Altitudinal variability of climate-tree growth relationships along a consistent slope of Anyemaqen Mountains, northeastern Tibetan Plateau. Dendrochronologia 26: 87-96.

Peterson D.W., Peterson D.L. 2001. Mountain hemlock growth responds to climatic variability at annual and decadal time scales. Ecology 82: 3330-3345.

Richman M.B. 1986. Rotation of principal components. Journal of Climatology 6: 293-335.

Rolland C. 1993. Tree-ring and climate relationships for Abies alba in the internal Alps. Tree-Ring Bull 53: 1-11.

Savva Y., Oleksyn J., Reich P.B., Tjoelker M.G., Vaganov E.A., Modrzynski J. 2006. Interannual growth response of Norway spruce to climate along an altitudinal gradient in the Tatra Mountains, Poland. Trees - Structure and Function 20: 735-746.
Splechtna B.E., Dobrys J., Klinka K. 2000. Tree-ring characteristics of subalpine fir (Abies lasiocarpa (Hook.) Nutt.) in relation to elevation and climatic fluctuations. Annals of Forest Science. 57: 89-100.

Takahashi K., Azuma H., Yasue K. 2003. Effects of climate on the radial growth of tree species in the upper and lower distribution limits of an altitudinal ecotone on Mount Norikura, central Japan. Ecological Research 18: 549-558.

Takahashi K., Tokumitsu Y., Yasue K. 2005. Climatic factors affecting the tree-ring width of Betula ermanii at the timberline on Mount Norikura, central Japan. Ecological Research 20: 445-451.

Takahashi K., Okuhara I., Tokumitsu Y., Yasue K. 2011. Responses to climate by tree-ring widths and maximum latewood densities of two Abies species at upper and lower altitudinal distribution limits in central Japan. Trees 25: 745-753.

Tardif J., Camarero J.J., Ribas M., Gutierrez E. 2003. Spatiotemporal variability in tree growth in the Central Pyrenees: Climatic and site influences. Ecological Monographs 73: 241-257.

Wang T., Ren H., Ma K. 2005. Climatic signals in tree ring of Picea schrenkiana along an altitudinal gradient in the central Tianshan Mountains, northwestern China. Trees - Structure and Function 19: 735-741.

Wigley T.M.L., Briffa K.R., Jones P.D. 1984. On the average value of correlated time series, with applications in dendroclimatology and hydrometeorology. Journal of Climate and Applied Meteorology 23: 201-213.

Wilmking M., Juday G.P., Barber V.A., Zald H.S.J. 2004. Recent climate warming forces contrasting growth responses of white spruce at treeline in Alaska through temperature thresholds. Global Change Biology 10: 1724-1736.

Wu D.D., Zhou Y.B., Yu D.P., Dai G.H. 2009. Physiological response of Betula ermanii at different altitudes in Changbai Mountain. Acta Ecologica Sinica 29: 2279-2285 (in Chinese, English summary).

Yu D., Wang G.G., Dai L., Wang Q. 2007. Dendroclimatic analysis of Betula ermanii forests at their upper limit of distribution in Changbai Mountain, Northeast China. Forest Ecology and Management 240: 105-113.

Yu D.P., Gu H.Y., Wang J.D., Wang Q.L., Dai L.M. 2005. Relationships of climate change and tree ring of Betula ermanii tree line forest in Changbai Mountain. Journal of Forestry Research 16: 187-192.

Zhang Q.B., Hebda R.J. 2004. Variation in radial growth patterns of Pseudotsuga menziesiion the central coast of British Columbia, Canada. Canadian Journal of Forest Research 34: 1946-1954. 